FORMAÇÃO HUMANA E COMPETÊNCIAS: O DEBATE NAS
DIRETRIZES CURRICULARES DE PSICOLOGIA FORMACIÓN HUMANA Y COMPETENCIAS: EL DEBATE EN LAS DIRECTRICES CURRICULARES EN PSICOLOGÍA HUMAN FORMATION AND COMPETENCIES: THE DEBATE ON CURRICULUM GUIDELINES FOR PSYCHOLOGY

\author{
Vinicius Cesca de Lima \\ Pontifícia Universidade Católica de São Paulo, São Paulo/SP, Brasil
}

Régis de Toledo Souza

Universidade de Taubaté, Taubaté/SP, Brasil

\begin{abstract}
RESUMO
O artigo analisa as perspectivas de formação humana e de desenvolvimento de competências identificadas nas Diretrizes Curriculares Nacionais para os Cursos de Graduação em Psicologia. A partir da crítica aos processos modernos de formação humana, realizada pela Teoria Crítica da Sociedade, analisamos sua institucionalização em práticas escolares, incluindo a pedagogia por competências, e mais especificamente na educação universitária. Por fim, discutimos essas questões na formação de psicólogos. Confrontando as propostas de formação para a emancipação e de formação para o desenvolvimento de competências, apontamos, a partir da matriz pautada nas Diretrizes Curriculares, que a formação em psicologia representa um processo contraditório que evidencia um projeto em disputa.
\end{abstract}

Palavras-chave: formação em psicologia; formação humana; competências.

\title{
RESUMEN
}

El artículo analiza las perspectivas de formación humana y de desarrollo de competencias identificadas en las Directrices Curriculares Nacionales para el Pregrado en Psicología. Desde la crítica de los procesos modernos de formación humana, realizada por la Teoría Crítica de la Sociedad, analizamos su institucionalización en las prácticas escolares, incluyendo la pedagogía por competencias, y más específicamente en la enseñanza universitaria. Finalmente, estos temas son discutidos en la formación de psicólogos. Confrontando las propuestas de formación para la emancipación y de formación para el desarrollo de competencias, señalamos, desde la matriz presente en las Directrices Curriculares, que la formación de psicólogos es un proceso contradictorio que expresa un proyecto en disputa.

Palabras-clave: pregrado en psicología; formación humana; competencias

\begin{abstract}
This article analyzes the perspectives of human formation and competencies development as identified in Brazilian National Curriculum Guidelines for Undergraduate Courses in Psychology. From the critique of modern processes of human formation, as discussed by Critical Social Theory, the analysis focused on its institutionalization in school practices, included the competencies pedagogy, and specifically in universitary education. Then, these issues are discussed in psychologists' formation. Comparing the proposes of emancipatory formation and formation oriented to developing competencies, it is pointed out, debating on Curriculum Guidelines, that psychologists' formation represents a contradictory process that reveals a project in dispute.
\end{abstract}

Keywords: psychology undergraduate; human formation; competencies. 
Muitos questionamentos, incertezas e inquietações vêm à tona quando nos referimos ao processo de formação de psicólogos. Em discussão sobre o papel social da Universidade, Chauí (2001) nos apresenta um cenário geral, que assumimos como também sendo o da formação em Psicologia, em que se questiona a qualidade da capacitação profissional possibilitada pela universidade, a garantia de emprego e trabalho outrora representada pelo diploma, a utilidade e aplicabilidade dos conhecimentos transmitidos, sua excessiva tecnização e instrumentalização, a fragilidade de referenciais para o pensamento crítico, o compromisso elitista da formação, a validade dos currículos e dos programas educacionais.

Aaprovação das Diretrizes Curriculares Nacionais para os cursos de graduação em Psicologia (Conselho Nacional de Educação - CNE, 2004) representou a proposta e promessa de implementação de uma nova concepção para a formação de psicólogos, visando a superar essas incertezas e inquietações. Contudo, ao mesmo tempo em que imprimiu um tom esperançoso, gerou questionamentos sobre sua aplicação e sua plena tradução em novos projetos pedagógicos.

Apresentaremos, por conseguinte, alguns elementos para problematizar a formação em Psicologia a partir da análise das Diretrizes Curriculares e sua proposta de desenvolvimento de competências - noção que entendemos ser central - e como essas podem ser entendidas em uma perspectiva de formação humana. Recorremos à Teoria Crítica da Sociedade, mais especificamente aos escritos de Theodor W. Adorno e de Max Horkheimer, para fundamentar esta análise, a partir da crítica aos processos de formação humana possibilitada pelos conceitos de razão instrumental, indústria cultural e semiformação e os consequentes desdobramentos à formação psicossocial como um campo de preocupações da Psicologia Social.

$\mathrm{O}$ texto foi dividido em quatro partes. A primeira discute concepções de formação humana, realizando uma primeira aproximação teórica que permite compreender, posteriormente, a constituição da educação escolar formal e prepara o debate sobre a formação de psicólogos. A segunda parte aprofunda a discussão para a compreensão de como as concepções de formação humana apresentadas embasaram a emergência da escola, como a instituição à qual coube a função de mediar os processos formativos, e mais especificamente da universidade, em cujo interior se constitui a formação de psicólogos. Em seguida, procuramos explicitar como se constitui a ideia de uma educação voltada ao desenvolvimento de competências. Após uma delimitação conceitual e teóricometodológica da noção de competência, exploramos como essa se tornou, contemporaneamente, a noção central na organização do trabalho e nas propostas pedagógicas. Por fim, discutimos essas questões na formação em Psicologia.

\section{Formação humana}

A educação, na cultura ocidental, sempre foi concebida como atividade de formação humana, noção que se assenta na perspectiva de que o homem não nasce pronto e precisa, no decorrer de sua vida, se humanizar, avançar em sua condição de ser cultural (Severino, 2006).

O processo do que podemos assim compreender como formação humana ocorre através da apropriação do patrimônio material e espiritual acumulado, em cada momento histórico, pela humanidade, e o impedimento de uma apropriação plena também é o impedimento do pleno desenvolvimento dos indivíduos enquanto seres integralmente humanos. Na sociabilidade capitalista, a partir da centralidade assumida pelo trabalho abstrato, a subordinação dos processos de formação humana aos imperativos de produção da riqueza resulta em uma formação unilateral, profundamente cindida entre formação cultural e formação para o trabalho (Tonet, 2006).

Esta problemática, das limitações e possibilidades da formação humana na modernidade, foi objeto privilegiado das reflexões dos filósofos da Escola de Frankfurt, através da análise da dialética da razão iluminista. A partir de suas contribuições, faremos alguns apontamentos que permitem delimitar uma análise crítica da formação de psicólogos.

Em Dialética do Esclarecimento (2006), Horkheimer e Adorno demonstram como o processo de implantação do projeto civilizatório moderno produziu, contraditoriamente, a partir do ideal iluminista de razão emancipatória, o seu oposto, a razão instrumental. O programa original do esclarecimento, de desencantamento do mundo, desvirtuou-se, desta forma, ao colocar-se a serviço exclusivo do progresso representado pela economia burguesa: a razão instrumental toma a realidade como seu objeto de investigação exclusivamente com os fins de controle e dominação técnica da natureza, processo controlado pelos interesses da atividade industrial capitalista. A razão instrumental não libertou o homem, como prometia o projeto iluminista, mas o aprisionou. Operou-se a inversão do programa original da emancipação da razão: a técnica que serviria de instrumento para o homem dominar a natureza e garantir sua conservação e reprodução se 
torna ela mesma instrumento de subjugação do próprio homem, tendo como consequência a reificação de sua consciência.

Horkheimer e Adorno (2006) indicam ainda que a razão instrumental é totalitária. Tudo o que não pode se submeter a seus critérios de calculabilidade e utilidade torna-se suspeito, dando origem a uma forma de organização social, dominada pela lógica do equivalente, quantificado, calculável e previsível, que eles denominaram "sociedade administrada". Essa organização do mundo, convertida a si mesma imediatamente em sua própria ideologia (Adorno, 2006), torna a tudo mercadorias, tendo por consequência a massificação dos próprios homens. Opera-se assim a revogação do sujeito. A massificação da individualidade imposta por sua subordinação à técnica levou à dissolução das possibilidades de autodeterminação dos homens, transformando em heteronomia a sonhada emancipação dos homens e em massa amorfa o que aspirava ser sociedade esclarecida.

Entre todas as formas de instrumentalização operadas pela sociedade administrada, uma recebeu destaque nas análises dos teóricos críticos: essa racionalidade, ao atingir o plano da produção simbólica, da cultura, dá origem ao que denominaram Indústria Cultural (Horkheimer \& Adorno, 2006). Na sociedade dominada pela razão instrumental, a produção cultural se dá de acordo com as determinações sociais que orientam a produção em massa de mercadorias, incorporando a racionalidade técnica da ciência e do planejamento administrativo e operando pela lógica da acumulação capitalista (Costa, 2009).

O que a Indústria Cultural oferece é "a liberdade de escolher o que é sempre a mesma coisa" (Horkheimer \& Adorno, 2006, p. 138). Seu produto é um "simulacro de cultura para consumo pessoal" (Costa, 2009, p. 70). Pelo poder coercitivo que exerce, dissipa-se a autonomia, homogeneízam-se as subjetividades, reduz-se o sujeito a indivíduo passivo, surge a massa. Deste modo, produzindo o que Adorno (1996) denomina semicultura, a Indústria Cultural passa a exercer o papel de aparato de reprodução ideológica da sociedade administrada.

A problemática da instrumentalização da cultura assume significado fundamental para a compreensão da formação humana como formação cultural (Costa, 2009), como a apropriação subjetiva da cultura (Adorno, 1996). A formação cultural produzida em uma sociedade dominada pela lógica do equivalente, em que impera a razão instrumental e a fetichização da técnica e da mercadoria, de homens massificados cuja consciência é reificada pelo aniquilamento subjetivo imposto pela Indústria Cultural, é denominada por
Adorno (1996) como semiformação. A semiformação, enquanto determinação social de um padrão de subjetividade, identifica-se por revogar justamente o elemento que caracteriza a formação cultural, a autodeterminação dos indivíduos, constituindo-se no impedimento fundamental para a emancipação humana (Adorno, 2006).

Nesse contexto, segundo Adorno (2006), três grandes objetivos formativos impõem-se à educação: favorecer o desenvolvimento de uma autoconsciência crítica, impedir a repetição da barbárie perpetuada pelos aspectos irracionais da razão instrumental e fornecer as condições para a emancipação e a autodeterminação dos indivíduos. O que somente é possível se a educação for "uma educação para contradição e para a resistência" (Adorno, 2006, p. 183), estabelecendo, através de autorreflexão crítica, uma relação dialética com a semiformação real em que se converteu (Adorno, 1996). A concepção de formação cultural emancipatória como resistência à semiformação real decorre da constatação, por Adorno (2006), de que é impossível desvencilhar completamente a educação de sua função adaptativa, sob o risco de se formarem mônadas sociais destituídas das competências mínimas para a vida em sociedade. Desta forma, como aponta Costa (2009), a possibilidade de superação do momento adaptativo da educação é clarificá-lo em seu próprio âmbito, tornando objetos refletidos os processos que ora empurram-na para a adaptação, ora pretendem colocá-la a serviço da emancipação, possibilitando assim a fixação de alternativas históricas possíveis para a emancipação de todos como sujeitos refletidos da história (Maar, 2006).

\section{Formação institucionalizada}

A partir das referências de constituição do ideal de humanização colocado pela modernidade e suas contradições no plano cultural e da formação, podemos avançar na compreensão de como essas concepções se relacionam a práticas educativas escolares.

O caráter historicamente elitista da educação como desenvolvimento de valores éticos e de "cultivo do espírito" da pequena elite dirigente à qual cabia o trabalho intelectual - em contraposição aos trabalhadores manuais a quem não se atribuía a necessidade de qualquer formação educacional e escolar (Tonet, 2006) - modificou-se com a consolidação dos ideais da modernidade. A partir da necessidade de aproximar o recém-aclamado cidadão livre dos novos valores e da nova visão de mundo que agora se organizava de acordo com os princípios da razão esclarecida, o acesso à educação haveria de ser 
universalizado, como instrumento de popularização do saber e dos conhecimentos fundados no progresso da razão (Costa, 2009). Estabeleceu-se, assim, de forma inédita, uma política educacional, definida por Zanotti (citado por Patto, 1999, p. 41) em termos de uma "ação sistemática e permanente do Estado dirigida à orientação, supervisão e provisão do sistema educativo escolar". A definição de uma política educacional, por sua vez, levaria à implementação de sistemas nacionais de ensino.

O fortalecimento da escola enquanto instituição social, levando-a a ser, doravante, irreversivelmente alçada à condição de setor vital ao desenvolvimento social, se deu, portanto, em íntima relação com a consolidação do modelo social, político e econômico burguês, pela necessidade emergente de um sistema sempre mais complexo de aprendizagem técnicoprofissional e de um aparato sempre renovável de controle ideológico, condições que perpassam estruturalmente a instituição escolar e definem sua função social desde então (Patto, 1999).

A escola passou, dessa forma, a exercer o duplo papel de conduzir os indivíduos a uma visão mais racional do mundo através de sua iniciação no pensamento científico e prepará-los para a inserção na esfera do trabalho. Este duplo papel decorre da aceitação, que se converte mesmo em aclamação, da divisão social do trabalho em intelectual e manual. A contradição entre formação cultural e formação para o trabalho, centro das contradições presentes na concepção moderna de formação humana, se torna assim fator estruturante da instituição escolar.

A universidade moderna, por sua vez, distinguindo-se da escola básica e seu pretenso caráter universal, se constituiu atrelada à ideia de formação de alto nível, "superior", dirigida às elites econômicas, políticas e culturais (Chauí, 2001). Surge, na segunda metade do século XVIII, como um dos pilares de sustentação do Estado moderno, no interior do qual exerceria as funções de formar uma burguesia intelectual para substituir a nobreza na gestão da esfera pública e forjar uma tradição nacional que legitimasse culturalmente a recém-conquistada soberania política e militar (Musse, 2009).

Contudo, o aprofundamento do projeto político liberal e do modelo capitalista de produção, especialmente com o advento do capitalismo de Estado, levou a universidade a exercer uma terceira função primordial: a de "fornecer o saber técnico-científico imprescindível ao planejamento, programação e controle do processo de produção e circulação de mercadorias" (Musse, 2009, p. 57). Desta forma, ao se aproximar cada vez mais das demandas e exigências de mercado, a universidade moderna abandonou seu papel de formação cultural das elites, de produção e transmissão de cultura, assumindo, de forma gradual e irreversível, a função de adestrar mão de obra altamente especializada (Chaúí, 2001).

No caso nacional, as reformas modernizantes das universidades se deram no contexto que sucede o golpe de 1964, quando a universidade foi aclamada como "instrumento de aceleração do desenvolvimento, instrumento do progresso social e da expansão de oportunidades, vinculando a educação aos imperativos do progresso técnico, econômico e social do país" (Chauí, 2001, p. 47). No contexto de modernização propiciado pelo "milagre econômico" dos anos 1970, a universidade brasileira, oferecida como prêmio de consolação à classe média despojada do poder, base de sustentação político-ideológica do regime ditatorial, converteu-se aos modelos que Chauí (2001, p. 189) denomina "universidade funcional" $\mathrm{e}$ "universidade de resultados". Voltada diretamente ao mercado de trabalho e adaptada às suas exigências, a universidade se foca na formação de mão de obra altamente qualificada, obtendo do sistema produtivo, como contrapartidas, a absorção dos quadros formados e o financiamento de suas pesquisas, ligadas diretamente aos interesses de mercado. Os empregos e a utilidade imediata do conhecimento produzido por suas pesquisas passam a ser apresentados pela universidade como legitimação de sua existência institucional.

Esse modelo foi substituído no bojo das transformações advindas da adesão da universidade à política neoliberal e da desregulação promovida pela tese do "Estado mínimo", na década de 1990, contexto no qual a concepção de educação enquanto direito foi suplantada pela concepção de educação enquanto serviço. A diminuição do papel do Estado, proposta pelo ideário neoliberal, insere a educação no rol daqueles entendidos como serviços não exclusivos do Estado, convertendo-a em mercadoria comercializada por organizações escolares prestadoras de serviços. Este contexto de transformações sociais, políticas e econômicas operou uma mudança importante em sua concepção: de instituição social, a universidade contemporânea converteu-se em organização social, definida em termos de sua instrumentalidade. A "universidade de resultados" é substituída assim pela "universidade operacional" (Chauí, 2001, p. 190). As ideias de avaliação, produtividade e eficácia são rapidamente absorvidas e passam a balizar a atividade acadêmica, adotando, no campo educativo, o léxico característico do pensamento neoliberal, com suas ideias de qualidade total, formação 
polivalente, flexibilidade, participação, autonomia, descentralização e, como passaremos a explorar, competência. Dessa forma, dissimula-se o conflito entre formação cultural e formação profissional no interior da universidade, que é levado ao seu extremo, mas cindido, fragmentado, ocultando a contradição. Processo semelhante se dá na relação entre escola e cultura, que "se relacionam, mas seguramente não são coincidentes" (Canêdo, 2009, p. 437).

\section{Formação de competentes}

O debate pedagógico contemporâneo tem privilegiado a noção de competências e sua pertinência. A questão das competências e da relação conhecimentos/competências está no centro de reformas curriculares e dos sistemas educacionais em diversos países, apontando até para uma adoção indiscriminada (Machado, 2002; Perrenoud, 1999).

Apontada como multidimensional, multifacetada, complexa e polissêmica (Manfredi, 1998; M. Ramos, 2006), a noção de competências se dissipa em uma rede desconexa de significados que dificulta sua definição e sua apreensão, diante do que adotamos certa suspeição. Compartilhamos a análise realizada por Horkheimer e Adorno (1973) de que a fragmentação das funções sociais resultante da divisão social do trabalho tornou a sociedade moderna imperceptível em sua totalidade e em suas motivações, o que lhe confere uma aparência de complexidade que oculta o modo de operar do mecanismo social que obstrui o caminho para a compreensão do todo. Em vista disso, procuramos fazer os apontamentos possíveis para apreender a noção de competências nos diversos contextos em que é utilizada, de modo a delinear suas principais características conforme sejam úteis para nossa proposta de discussão.

Etimologicamente, a palavra competência decorre, segundo Saraiva (citado por Alessandrini, 2002, p. 164), do termo latino competentia, que pode ser traduzido por "proporção" ou "simetria" e indica a capacidade de reagir de forma adequada, proporcional, a uma situação determinada (Alessandrini, 2002). Surge no universo da linguagem jurídica para se referir ao direito que uma jurisdição tem de apreciar e julgar causas específicas, remetendo à ideia central de limite: o que define uma competência é a delimitação dos trabalhos que ela permite realizar (Rey, 2002).

Dessa ideia de delimitação decorre a necessidade de explicitar as maneiras segundo as quais as competências se manifestam e se materializam, nos âmbitos em que se inserem (Machado, 2002). Introduz- se, assim, a ideia complementar de habilidades, relacionadas ao "saber fazer" e que expressam a forma pela qual uma competência se realiza.

Da linguagem jurídica, a noção de competência é apropriada pelo universo conceitual das ciências cognitivas - a linguística e especialmente a psicologia - das quais adquire os fundamentos dos significados que assume atualmente nos campos do trabalho e da educação. Compondo o repertório teórico da Psicologia do Desenvolvimento, da Psicologia da Aprendizagem e da Psicometria (Manfredi, 1998), a noção de competência pode ser compreendida a partir de três matrizes referenciais teórico-metodológicas: 0 condutivismo, o funcionalismo e o construtivismo (M. Ramos, 2006).

Definida enquanto comportamento, na concepção condutivista, a ideia de competência se identifica com as ideias de desempenho efetivo, eficácia, de padrão de resultados desejados (M. Ramos, 2006). Advém, como aponta Rey (2002), de uma perspectiva objetivista, cientificista e racionalista, podendo ser definida pelos comportamentos que engendra.

$\mathrm{Na}$ teoria funcionalista, por sua vez, a noção de competência é focada em resultados, naquilo que uma pessoa deve fazer ou estar em condições de fazer, definindo-se em termos de sua finalidade técnico-social (M. Ramos, 2006; Rey, 2002). Uma competência, neste modelo, é aquilo que concorre para o adequado funcionamento e equilíbrio do sistema analisado, o que lhe confere um caráter adaptativo (M. Ramos, 2006).

Por fim, na abordagem construtivista, uma competência é definida pela combinação de conhecimentos, experiências e comportamentos que se exercem em um determinado contexto, o que representa a integração de três saberes: o saber, o saber fazer e o saber ser, resultando em um "ser capaz de" (M. Ramos, 2006, p. 96). Caracteriza-se ainda pela capacidade de mobilizar atributos cognitivos e socioafetivos para enfrentar diversas situações cotidianas (Machado, 2002). Esta concepção, conforme indica Rey (2002), funda um novo modelo, divergente dos anteriores, pois descola o foco das competências de um fator externo, observável, objetivo, para um fator subjetivo.

Como síntese, M. Ramos (2006) aponta que a noção de competência, não importa o modelo teóricometodológico, fundamenta-se em uma concepção natural-funcionalista de homem e sua correlata concepção subjetivo-relativista de conhecimento. Em suas características fundamentais, guarda, dessa forma, coerência com o discurso ideológico que sustenta o ideário político-econômico neoliberal, relação esta que pode ser ainda mais visivelmente 
percebida quando analisamos os processos sociais e históricos que tornaram a noção de competências uma ideia ordenadora no trabalho e na educação.

A noção de competências assumiu destaque, a partir da década de 1980, no contexto das mudanças tecnológicas e de organização do trabalho que configuraram a chamada reestruturação produtiva, em decorrência da imposição de novas exigências oriundas de novos modelos de produção e gerenciamento. Sua ascensão, nesse contexto, se torna possível a partir do que M. Ramos (2006) denomina como um deslocamento teórico e material do conceito de qualificação profissional.

O conceito de qualificação profissional, conforme discutido por Manfredi (1998) e M. Ramos (2006), surgiu no marco do Estado de Bem-Estar Social como resposta à ausência de regulações sociais no campo do trabalho, objetivando "reconhecer o trabalhador como membro de um coletivo dotado de um estatuto social" (M. Ramos, 2006, p. 42). Situa-se na intersecção entre as esferas do trabalho e da educação, assumindo a função de ordenador das relações entre essas na materialidade do mundo produtivo. Enquanto conceito, a qualificação profissional representa, desta forma, uma relação social concreta, entre trabalho e capital, inserida no "plano de disputa entre os projetos econômico-políticos da classe trabalhadora e da classe burguesa" (M. Ramos, 2006, p. 25).

No modelo de organização do trabalho taylorista/ fordista, destacavam-se as dimensões conceitual e social da qualificação, que remetem aos códigos formais da formação profissional requerida para o desempenho de cada função e ao reconhecimento social do conteúdo e dos limites de determinada atividade profissional. Contudo, as mudanças tecnológicas e de organização do trabalho decorrentes da implantação do modelo toyotista vieram a estabelecer o marco de um novo profissionalismo, caracterizado pela multifuncionalidade e polivalência, pela mobilidade entre ocupações, pela desqualificação sistêmica e manutenção de margem de desemprego estrutural, pela precarização das relações de trabalho e flexibilização das atividades profissionais e dos direitos trabalhistas.

Nesse contexto, como resultante destas novas demandas, negam-se as dimensões conceitual e social da qualificação e emerge o conceito de competência, que passou a atender a, pelo menos, três propósitos:

a) reordenar conceitualmente a compreensão da relação trabalho-educação, desviando o foco dos empregos, das ocupações e das tarefas para o trabalhador em suas implicações subjetivas com o trabalho; b) institucionalizar novas formas de educar/ formar os trabalhadores e gerir o trabalho ... sob novos códigos profissionais; c) formular padrões de identificação da capacidade real do trabalhador para determinada ocupação, de tal modo que possa haver mobilidade entre as diversas estruturas de emprego. (M. Ramos, 2006, p. 39)

Esse deslocamento apresentou, como sua principal consequência, a ascendência da dimensão psicológica da qualificação sobre as dimensões econômica, sociológica, ético-política e pedagógica. A noção de competências, portanto, ao hegemonizar o discurso de qualificação profissional no contexto da reestruturação produtiva, se torna instrumento de aprisionamento da subjetividade do trabalhador às necessidades de reprodução do capital em sua nova "roupagem", diante de relações de trabalho que, se transformadas em sua forma, são plenamente conservadas em seu conteúdo.

Com a consolidação do projeto neoliberal, por conseguinte, a noção de competência foi transposta para o discurso educacional. Diante da necessidade de formação de quadros adequados a essa nova realidade de trabalho, o desenvolvimento de competências como proposta pedagógica, em uma perspectiva eminentemente técnica e instrumental, é adotado indiscriminadamente pelo meio educacional, a partir da década de 1990, no curso das reformas dos sistemas de ensino amparadas no neoliberalismo hegemonizado.

A pronta adesão ao discurso competente relaciona-se ainda, como aponta Perrenoud (1999), aos conflitos sofridos pela própria escola em sua busca de justificar e legitimar sua existência enquanto instituição social, reanimando um debate que opõe as defesas da transmissão cultural em si e da necessidade de ligação imediata do conhecimento a práticas sociais. Dessa forma, a apropriação da noção de competências pelo discurso educacional atualiza o conflito entre formação cultural e formação profissional, que perpassa a instituição escolar.

Analisando a perspectiva de formação humana possibilitada pelo modelo educacional baseado em competências, apontamos para suas limitações enquanto formação cultural que possibilite a emancipação e o desenvolvimento de uma autoconsciência crítica, na perspectiva defendida por Adorno (2006). Para além da crítica a um modelo educacional específico, partimos da análise de que sua proposta, enquanto manifestação social e histórica, reflete as contradições e limitações de um ordenamento social que restringe, se não impede, a realização plena dos sujeitos que nele se inserem. Inscrita na lógica social vigente, contra a qual não elabora qualquer crítica, mas com a qual, 
ao contrário, guarda identidade enquanto mecanismo ideológico, a formação por competências se efetiva tão somente como semiformação.

Na cisão entre os aspectos teóricos e espirituais da cultura e os seus aspectos práticos e materiais, na qual se encontram as origens da semiformação, a noção de competência toma posição ao lado da prática. Mas, tão somente da prática que pode ser justificada como útil, funcional e que atenda a determinados apelos políticoeconômicos. Limitando-se ao pragmatismo produtivo, portanto, a ênfase na prática posta pela noção de competência impede que a ação humana no mundo se torne emancipatória enquanto práxis, efetivandose apenas como força reprodutora dos processos de acumulação de capital.

O direcionamento aos aspectos subjetivos da formação, promovido pela noção de competência, que poderia trazer em si a possibilidade de emancipação, em coerência com a proposta crítica de "inflexão em direção ao sujeito” (Adorno, 2006, p. 121), é reduzido e rendido por uma concepção massificadora, heterônoma, que adapta as subjetividades aos imperativos de um sistema econômico, político e social aprisionador, deformando-as ao invés de formá-las. O deslocamento de referenciais coletivos e sociais para um referencial subjetivo-individual realiza-se de modo a instrumentalizar as consciências, reificando-as. Os recursos cognitivos e socioafetivos são transformados em meras ferramentas de trabalho, que passam a ser vendidas e compradas como mercadorias.

As origens da noção de competência em abordagens psicológicas que adotam modelos teóricoepistemológicos de base experimental e positivista situam-na, ainda, como mecanismo a serviço da psicologização das questões sociais, inscrevendo-a no limite da racionalidade tecnológica.

A abordagem pedagógica por competências deve ser compreendida, ainda, no âmbito do que Adorno (2006) denominou por escola administrada. Convertida a educação em mercadoria, e enquanto meio privilegiado de comercialização dos simulacros culturais veiculados pela Indústria Cultural, o produto com que trabalha a escola contemporânea é o desejo de preparar o indivíduo para o mercado de trabalho. Neste contexto, C. Ramos (2007) aponta que a embalagem com que é revestido o produto educacional são os novos recursos tecnológicos aplicados à educação, enquanto "técnicas modernas de ensino", incluindo-se a pedagogia das competências enquanto instrumento de hiper-racionalização dos processos educativos que torna a escola uma organização social administrada como qualquer outra, reprodutora dos determinantes de uma formação corrompida em semiformação.
Por fim, neste momento de nossa análise, devemos considerar que a noção de competência, cuja aparência é tornada tão complexa e cujos significados são diluídos em uma rede desconexa de definições e enfoques, oculta ideologicamente uma formação que sequer pode se realizar por completo mesmo em sua versão instrumentalizada. Analisando o papel da universidade, Chauí (2001, p. 44) faz uma consideração essencial quando afirma que o papel da educação é criar incompetentes sociais e políticos, realizando "com a cultura o que a empresa realiza com o trabalho, isto é, parcelar, fragmentar, limitar o conhecimento e impedir o pensamento".

\section{Formação de psicólogos}

A partir dos referenciais estabelecidos, podemos compreender a formação de psicólogos como uma formação inserida na cisão entre formação cultural e formação profissional, institucionalizada em uma universidade adaptada ao ideário neoliberal e que adota a pedagogia das competências como seu modelo educativo. Consideramos, contudo, que outros dois elementos têm de ser considerados na análise crítica do modelo proposto pelas Diretrizes Curriculares para os cursos de graduação em Psicologia.

O primeiro é o fato de que a Psicologia mantém íntima relação de cumplicidade com o projeto burguês de modernidade, se legitimando como instrumento de legitimação desse projeto, o que se deu, segundo Adorno (2001), pela ascensão da concepção de indivíduo através da "fraude abissal do puramente íntimo" (p. 61). Da mesma forma, Adorno explicita que a psicologia, ao converter o sujeito humano em seu objeto, forneceu as condições para a opressão e dissolução deste mesmo indivíduo, em um processo de fracionamento dos homens que é "inseparável do interesse em fornecer-lhes a máxima utilidade, para os poder manipular" (Adorno, 2001, p. 61).

Coube, dessa forma, à psicologia e aos psicólogos, no interior da sociedade administrada, a função de adaptar o indivíduo, contribuindo assim para a revogação de sua autonomia e autodeterminação. Oliveira (2005, pp. 15-16) aponta, com isso, que o papel social da profissão de psicólogo decorreu da promessa de servir à racionalização dos processos sociais, de que "através dos instrumentos de avaliação psicológica, seríamos uma profissão fundamental para o gerenciamento da sociedade no processo de modernização".

Assim, os discursos modernizantes e racionalizantes apresentados pela Psicologia às elites 
econômicas, políticas e culturais, que permitiram e legitimaram sua posição social, atrelaram a formação de psicólogos, no percurso histórico, aos processos de modernização e racionalização da formação humana, da formação profissional e da formação universitária. Desta relação fundacional a formação em Psicologia não se desvencilharia, nem mesmo quando assim se intencionou, por exemplo, com a aprovação das atuais Diretrizes Curriculares (Bernardes, 2004).

Um segundo elemento a ser considerado é o de que a própria noção de currículo escolar representa um procedimento de seleção cultural, que traz, por conseguinte, elementos de degradação da cultura em semicultura, característicos dos processos de semiformação, se inserindo, desta forma, nos processos sociais mais gerais de formação. Cabe a uma análise crítica, portanto, identificar que critérios de seleção cultural estão sendo utilizados. $\mathrm{Na}$ formação de psicólogos, estes são delineados a partir do que as Diretrizes estabelecem como sendo seus princípios e compromissos, objetivos gerais, eixos estruturantes, competências e habilidades visadas.

Identificamos, assim, que as Diretrizes Curriculares de Psicologia produzem um duplo registro, ora apontando para a realização plena da formação de psicólogos enquanto processo formativo que permita o esclarecimento e a emancipação do sujeito formado, ora apontando para a negação desse caráter transformador, aprisionando-o à ideologia instrumental de mercado.

Esse registro guarda coerência com o fato de a Psicologia, enquanto disciplina científica específica, se constituir como um campo marcado pela contradição fundamental de ser uma ciência que se propunha objetiva no estudo da subjetividade (Gonçalves, 2009). Deste conflito tipicamente moderno, que é sua dicotomia constitutiva, entre objetividade e subjetividade, não viria a se desvencilhar em seu desenvolvimento histórico, simultaneamente negando e afirmando ambas as perspectivas.

O desenvolvimento da Psicologia é ainda marcado por uma contradição não superada entre ciência e profissão. Reproduz-se, com isso, de forma especialmente intensa, no cenário da formação de psicólogos, a cisão entre cultura teórica, sublime, espiritual e cultura mundana, material, prática, que perpassa as instituições e práticas educativas. No que se refere a este cenário específico, o da formação em Psicologia, podemos identificar, ainda, a consolidada tendência de uma formação eminentemente técnica, desde as primeiras propostas curriculares.
Nas Diretrizes, esta cisão entre ciência e profissão explicita-se já em seus primeiros enunciados, quando o texto legal diferencia a formação voltada à atuação profissional, à pesquisa e ao ensino. Que esta cisão é tida como polarização, de forma dicotomizada, se explicita, adiante, quando as Diretrizes Curriculares tratam dos eixos estruturantes. Se, por um lado, temos os eixos "fundamentos epistemológicos e históricos" e "fundamentos teórico-metodológicos", que apontam para uma apreensão crítica da Psicologia, esses são tratados desvinculados da prática profissional, que constituem um eixo exclusivo, orientado pela noção de competências, nas Diretrizes Curriculares traduzidas em termos de "desempenhos e atuações", sustentados no domínio de conhecimentos apreendidos por um viés utilitarista. Dessa forma, a reflexão crítica proposta perde seu caráter de promoção de uma formação para a emancipação, fortalecendo a retórica da prática eficiente e determinando a semiformação.

Destacamos ainda a presença de outra esfera contraditória no processo que viria a originar as Diretrizes Curriculares Nacionais. A Psicologia brasileira, na década de 1980, atravessou um período de profundos questionamentos sobre os limites e as implicações de seus conhecimentos e intervenções. Aquela psicologia que tão bem serviu aos propósitos de dominação, controle e enquadramento no processo de desenvolvimento das sociedades modernas passou a ser denunciada e combatida por uma psicologia comprometida com a democracia social, com a promoção de direitos e da cidadania plena. No encontro, conflituoso e contraditório, entre este movimento interno, da categoria profissional de psicólogos e suas entidades, na direção da ruptura com o discurso fundacional da Psicologia, e um movimento externo, capitaneado pelo próprio Estado brasileiro, de revitalização da função discriminatória da Psicologia através de sua adaptação ao ideário neoliberal hegemônico, são construídas as atuais Diretrizes Curriculares.

Uma Psicologia que se posiciona politicamente, em sua prática profissional, ao lado da democracia social se explicita, nas Diretrizes, quando são determinados os princípios e compromissos fundamentais de uma leitura crítica da realidade que promova o exercício da cidadania e de uma atuação que considere as necessidades sociais, os direitos humanos e a promoção da qualidade de vida. A introdução dessas temáticas no cenário da formação é um avanço conquistado no curso da disputa política em torno da aprovação das Diretrizes Curriculares e serve para reafirmar a necessidade de uma formação que promova um compromisso ético-político da Psicologia. 
Contudo, a possibilidade de superação, no contexto da formação de psicólogos, do seu momento instrumental e reificador, que emerge nesse ponto de seu desenvolvimento histórico, foi absorvida pelo discurso educacional formal, por sua vez comprometido com a implantação do modelo neoliberal, como se nota pela adoção indiscriminada de seu vocabulário típico e da imposição velada dos valores que lhe são inerentes. Ao contrário de reafirmar o compromisso de uma formação que vise a uma intervenção transformadora, a definição das estratégias formativas, como apontadas pelas demais categorias conceituais das Diretrizes, se aproxima mais do discurso racionalizante e adaptativo original, que pouco tem a ver com uma leitura crítica da realidade.

Outra questão que levantamos é a proposta de uma formação generalista, identificada direta e indiretamente por todo o texto das Diretrizes Curriculares, quando estas apontam para uma formação que permita a atuação profissional em qualquer contexto a partir do desenvolvimento de competências e habilidades, gerais e transversais. A concepção de uma formação generalista, idealizada desde os debates realizados no interior dos cursos de graduação em Psicologia a partir da década de 1980 e da ampliação das chamadas "atuações emergentes", surge ante o desejo por romper com os modelos de intervenção clássicos, tidos por restritivos, e da tentativa de construção da unidade em meio à realidade fragmentada da formação de psicólogos. Tal desejo parece justificar certo entusiasmo na aceitação do modelo formativo baseado na noção de competência. De fato, o caráter flexível que lhe é implícito coadunava com a intenção de se dotar o formando de conhecimentos e habilidades genéricas que pudessem ser utilizadas a qualquer tempo em qualquer que fosse o contexto com que se deparasse. Contudo, a promessa de uma formação ampla e generalista, identificada com a ideia de competência, tem se mostrado insuficiente para romper as amarras conservadoras da formação em psicologia, visto que o modelo de competências se insere na própria tradição psicológica conservadora que se pretende através dele superar. O que temos, dessa forma, é uma forma peculiar de psicologização que torna a formação em psicologia refém do processo que busca racionalizar toda a realidade.

Todas essas contradições, uma vez não terem sido nunca esgotadas ou superadas no interior da Psicologia, mas, ao contrário, tendo sido de alguma forma reafirmadas pela implantação do modelo educacional por competências, se reproduzem no cenário da formação. Disso decorre que a proposta representada pelas Diretrizes Curriculares Nacionais para os cursos de graduação em psicologia rompe apenas parcialmente com o discurso fundacional da psicologia, mantendo, porém, intocados os pontos centrais (Bernardes, 2004). A despeito das transformações dos determinantes sociais ao longo da história, mantém-se a problemática fundamental na formação de psicólogos, relacionada ao ideal educativo moderno que emerge no século XIX. Esta percepção é essencial para evitar a retórica de que as Diretrizes Curriculares Nacionais representam um avanço em si, o que apenas esvazia a discussão e se presta a ocultar as contradições do processo.

Como alternativa, identificamos a necessidade de serem clarificados, no âmbito da formação em psicologia, os elementos contraditórios da própria psicologia e do próprio processo formativo. Essa proposta parte da constatação, feita por Adorno (2006), das limitações à mudança dos pressupostos objetivos sociais e políticos - da semiformação, sendo possível uma educação emancipatória na inflexão aos aspectos subjetivos, não pelo viés reificador de competências, mas pela promoção da consciência quanto à existência de elementos repressivos e opressivos no conceito de educação, mesmo naquela que se pretende culta.

Por sua vez, certos de ser arriscado falarmos de uma educação emancipatória como aquela que promove a consciência, é preciso atentar para não reproduzir a inversão ideológica operada por "fantasias inocentes e infantis" que atribuem a transformação da realidade à transformação da consciência, à crítica e à transformação das ideias e representações da realidade (Marx \& Engels, 2011, p. 523), e que tem como uma de suas expressões a concepção de que a educação adequada dos indivíduos basta para qualquer transformação social (Crochík, 1995). Por educação emancipatória como a que promove a consciência, nos referimos, portanto, à crítica que, sem abandonar a desmistificação das ideias que falseiam a realidade, desvela as condições concretas em que essas ideias são produzidas.

O esclarecimento dessas contradições na formação de psicólogos pode possibilitar uma apreensão crítica da própria psicologia, "no que essa contribui para a propagação da alienação humana, ainda que tenha intenções opostas" (Crochík, 1999, p. 28), de modo a se constituir em referência crítica "àquilo que ela vem afirmando ser o indivíduo, sem perceber que afirma a sua caricatura" (Crochík, 1999, p. 49). Apontamos uma possibilidade dessa apreensão crítica no direcionamento da formação em psicologia para os seus fundamentos epistemológicos, ontológicos e metodológicos, que atualmente se fazem presentes de 
forma ora subjugada aos aspectos práticos e técnicoprofissionais, ora desconexos desses.

Salientamos, contudo, e mais uma vez recorremos aAdorno (2006) para fazê-lo, que não se deve pretender abandonar as referências práticas, materiais e técnicoprofissionais na formação de psicólogos. Assim fazêlo seria semelhantemente ideológico, por favorecer o aparecimento de mônadas sociais incapazes de intervir na realidade com a intenção de transformála. Seria reforçar, apenas desde outra perspectiva, a cisão que impede que a formação se realize de forma plena. Seria cair vítima, por sua vez, da armadilha da desprofissionalização trazida pela implantação do projeto neoliberal e seu discurso de empregabilidade sustentado na noção de competências.

Por fim, atentamos ao caráter inacabado das reflexões sobre o problema. O campo de contradições e disputas que apontamos se insere em um campo mais amplo de disputas de rumos e significados entre distintos projetos societários, no qual se insere a psicologia. De sua origem como instrumento de controle e dominação, pode se constituir mecanismo de libertação e emancipação, propostas que coexistem e disputam concepções e projetos de profissão. Dessa forma, o registro dúbio e contraditório ocasionado pelas Diretrizes Curriculares reforça a necessidade de se assumir a formação de psicólogos como um projeto que precisa ser superado, como propõe Bernardes (2004), na direção de uma ruptura total com o saber atualmente instituído e da construção de outro campo de saber que não tenha a ver com o discurso fundacional da psicologia.

\section{Referências}

Adorno, T. W. (1996). Teoria da Semicultura (N. Ramos-deOliveira, B. Pucci, \& C. B. M. Abreu, Trads.). Educação e Sociedade, 17(56), $388-411$.

Adorno, T. W. (2001). Minima Moralia. Lisboa: Edições 70.

Adorno, T. W. (2006). Educação e emancipação. São Paulo: Paz e Terra.

Alessandrini, C. D. (2002). O desenvolvimento de competências e a participação pessoal na construção de um novo modelo educacional. In P. Perrenoud, M. G. Thurler, L. Macedo, N. J. Machado, \& C. D. Alessandrini, As competências para ensinar no século XXI: a formação dos professores e o desafio da avaliação (pp. 157 - 176). Porto Alegre: Artmed.

Bernardes, J. S. (2004). O debate atual sobre a formação em psicologia no Brasil - Permanências, rupturas e cooptações nas políticas educacionais. Tese de Doutorado, Programa de Estudos Pós-Graduados em Psicologia Social, Pontifícia Universidade Católica de São Paulo, São Paulo.

Canêdo, L. B. (2009). Escola versus cultura? Educação e Pesquisa, 35(3), 435-447.

Chaú, M. S. (2001). Escritos sobre a universidade. São Paulo: Editora UNESP.
Conselho Nacional de Educação - CNE (2004). Resolução CNE/CES $n^{\circ} 8$ de 7 de maio de 2004. Institui Diretrizes Curriculares Nacionais do curso de graduação em Psicologia. Brasília-DF: MEC.

Costa, D. S. (2009). O conceito de formação cultural na perspectiva educacional de Theodor Adorno. Monografia de Especialização, Departamento de Ciências Sociais e Letras, Universidade de Taubaté, Taubaté, SP.

Crochík, J. L. (1995). A (im)possibilidade da Psicologia Política. In M. A. Azevedo \& M. S. S. Menin (Orgs.), Psicologia e política: reflexões sobre a possibilidade e dificuldades deste encontro (pp. 13 - 56). São Paulo: Cortez.

Crochík, J. L. (1999). Notas sobre a formação ética e política do psicólogo. Psicologia \& Sociedade, 11(1), 27 - 51.

Gonçalves, M. G. M. (2009). A Psicologia como ciência do sujeito e da subjetividade: a historicidade como noção básica. In A. M. B. Bock, M. G. M. Gonçalves, \& O. Furtado (Orgs.), Psicologia sócio-histórica: uma perspectiva crítica em Psicologia ( $4^{\mathrm{a}}$ ed., pp. 37 - 52). São Paulo: Cortez.

Horkheimer, M. \& Adorno, T. W. (1973). Estudos da comunidade. In M. Horkheimer \& T. Adorno (Orgs.), Temas básicos da Sociologia (pp. 151 - 171). São Paulo: Cultrix.

Horkheimer, M. \& Adorno, T. W. (2006). Dialética do esclarecimento: fragmentos filosóficos. Rio de Janeiro: Jorge Zahar.

Maar, W. L. (2006). À guisa de introdução: Adorno e a experiência formativa. In T. W. Adorno, Educação $e$ Emancipação (4a ed., pp. 11 - 28). São Paulo: Paz e Terra.

Machado, N. J. (2002). Sobre a idéia de competência. In P. Perrenoud, M. G. Thurler, L. Macedo, N. J. Machado, \& C. D. Alessandrini, As competências para ensinar no século XXI: a formação dos professores e o desafio da avaliação (pp. 137-155). Porto Alegre: Artmed.

Manfredi, S. M. (1998). Trabalho, qualificação e competência profissional - das dimensões conceituais e políticas. Educação e Sociedade, 19(64), 13-49.

Marx, K. \& Engels, F. (2011). A ideologia alemã (1 ${ }^{\mathrm{a}}$ ed.). São Paulo: Boitempo.

Musse, R. (2009). Universidade de resultados. Revista Cult, $12(138), 56-58$.

Oliveira, M. V. (2005). A produção da identidade profissional no diálogo com o Estado. In III Seminário Nacional de Psicologia e Políticas Públicas (pp. 11-30). Brasília, DF: Conselho Federal de Psicologia.

Patto, M. H. S. (1999). A produção do fracasso escolar: histórias de submissão e rebeldia. São Paulo: Casa do Psicólogo.

Perrenoud, P. (1999). Construir as competências desde a escola. Porto Alegre: Artes Médicas Sul.

Ramos, C. E. (2007). A ideologia da racionalidade tecnológica: a educação no ensino superior como (semi)formação para o mercado de trabalho. Monografia de Especialização, Departamento de Ciências Sociais e Letras, Universidade de Taubaté, Taubaté, SP.

Ramos, M. N. (2006). A pedagogia das competências: Autonomia ou adaptação? ( $3^{\mathrm{a}}$ ed.). São Paulo: Cortez.

Rey, B. (2002). As competências transversais em questão. Porto Alegre: Artmed.

Severino, A. J. (2006). A busca do sentido da formação humana: tarefa da Filosofia da Educação. Educação e Pesquisa, $32(3), 619-634$.

Tonet, I. (2006). Educação e formação humana. Ideação, 8(9), $9-21$. 
Submissão em: 15/06/2012

Revisão em: 28/08/2012

Aceite em: 07/10/2012

Vinicius Cesca de Lima é mestre em Psicologia (Psicologia Social) pela Pontifícia Universidade Católica de São Paulo. Endereço: Rua Arão Areão, nº 223. Jardim Maria Augusta. Taubaté/SP. CEP 12070-040.

E-mail: viniciuscesca@gmail.com

Régis de Toledo Souza é doutor em Psicologia (Psicologia Social) pela Pontifícia Universidade Católica de São Paulo, Professor Assistente Doutor e Diretor do Departamento de Psicologia da Universidade de Taubaté. E-mail: regis.toledo.souza@gmail.com

\section{Como citar:}

Lima, V. C. \& Souza, R. T. (2014). Formação humana e competências: o debate nas diretrizes curriculares de Psicologia. Psicologia \& Sociedade, 26(3), 792-802. 